Cadernos de Clio, Curitiba, n. ${ }^{\circ}$ 4, 2013

\title{
REFLEXÕES SOBRE A HISTÓRIA SOCIAL DAS \\ MULHERES NA ANTIGUIDADE TARDIA: \\ O CASO DAS DEVOTAS CRISTÃS
}

João Carlos Furlani ${ }^{1}$

Resumo: Neste artigo, temos por objetivo refletir sobre a representação e as condições sociais em que se encontravam as mulheres entre o final do século III ao início do século V no Império Romano. Para tanto, discutiremos, num primeiro momento, o conceito de Antiguidade Tardia, bem como o contexto histórico da época; para, num segundo momento, analisarmos o papel desempenhado pelas mulheres cristãs na sociedade romana. Nesse sentido, acreditamos ser possível situar personagens femininas, que mesmo diante da repreensão atribuída às suas figuras, de certo modo, destacaram-se e tiveram voz em seu tempo.

Palavras-chave: Antiguidade Tardia; Império Romano; Mulheres; Cristianismo; Condição social.

\section{Introdução}

A segunda metade do século III é, tradicionalmente, considerada como um momento de agudas transformações do Império Romano, produzindo-se com rapidez alterações de natureza econômica, religiosa e política, o que proporcionou o surgimento de conflitos sociais que termi-

${ }^{1}$ Graduando do curso de História da Universidade Federal do Espírito Santo. Membro do Laboratório de Estudos sobre o Império Romano (LEIR) e do grupo de pesquisa em História de Roma da UFES. Atua na linha de pesquisa: "História social do Baixo Império Romano”, e no projeto “Cidade, corpo e poder no Império Romano”, sob orientação do prof. Dr. Gilvan Ventura da Silva. Atualmente, desenvolve o subprojeto intitulado: "Pobreza, caridade e liderança feminina na Antiguidade Tardia: o diaconato de Olímpia em Constantinopla”. Contato: joao.furlani@gmail.com. 
naram por desestabilizar o Estado. Tal mutação, além de gerar inquietações, acarretou diversas alterações na estrutura social do Império. Do ponto de vista religioso, intensificaram-se movimentos de desvalorização do mundo, com a irrupção de discussões cada vez mais acirradas. Por outro lado, novas visões de Estado, sociedade e religião emergiram, ao passo que papéis sociais tenderam a se modificar de modo mais ou menos rápido (Siqueira, 2010: 149-150). Esse período é amiúde identificado como o início da Antiguidade Tardia. Entretanto, as diversas mudanças supracitadas não ocorreram em um curto espaço de tempo como se costuma afirmar, pois há pelo menos um século já detectamos indícios de transformações que abrangem tanto a política quanto a religião, embora estas transformações tenham se tornado mais profundas nos séculos IV e V.

Inúmeros seriam os aspectos do século III a IV a serem estudados. No entanto, nos interessa destacar aqui questões relativas ao panorama social tardo-antigo. Desse modo, nosso objetivo principal, neste artigo, é refletir sobre a representação e as condições sociais em que se encontravam as mulheres entre o final do século III ao início do século V, no Império Romano, analisando o papel que desempenhavam na sociedade. Propomos-nos assim a analisar personagens que, mesmo diante da repressão que sofreram em virtude de serem mulheres, destacaram-se e tiveram voz em seu tempo. Nesse sentido, alguns conceitos acerca da História das Mulheres, como aqueles propostos por Michelle Perrot (1993), serviram de apoio à nossa pesquisa.

Perrot (1993) declara que as mulheres foram reprimidas por séculos, mas ressalta que sua história não é feita de violências e submissões. “O status de vítima não resume o papel das mulheres na história, que sa- 
bem resistir, existir, construir seus poderes” (Perrot, 1993: 166). De acordo com a autora, não podemos generalizar o status feminino, devemos compreendê-lo em suas variadas facetas e identidades. No entanto, compreender a identidade feminina como uma multiplicidade dinâmica de papéis sociais exige da análise historiográfica a visibilidade dos diversos contextos que possibilitaram a construção do lugar feminino ao longo do tempo (Caixeta, 2004).

Podemos perceber, ao analisarmos a História Social das Mulheres e a produção teórica sobre os estudos de gênero, que não existe um tipo único, mas representações variadas das mulheres em cada espaço-tempo. Muitas vezes essas distintas representações se articulam, assinalando uma identidade feminina contraditória, complexa e dinâmica, como a mulher no lar, no trabalho, nos contextos de sociabilidade, no exercício de sua sexualidade e de atividades religiosas (Condilo, 2009). Não nos prendendo aos diversos conceitos de identidade existentes, partimos do pressuposto de que a identidade feminina pode ser aquilo o que se diz e aquilo que se reconhece como características pertencentes às mulheres de determinado período.

\section{A Antiguidade Tardia, um momento de mudanças}

Compreender a condição social das mulheres na Antiguidade Tardia exige antes compreender o período a ser analisado, embora não possamos nos aprofundar aqui nesse assunto. No entanto, faz-se necessário dizer algumas palavras acerca do contexto histórico no qual viviam as mulheres que trataremos neste artigo. 
Cadernos de Clio, Curitiba, n. ${ }^{\circ}$ 4, 2013

Apoiando-nos no conceito proposto por Marrou (1979: 15), segundo o qual a Antiguidade Tardia "não somente é a última fase de um desenvolvimento contínuo: [mas] é uma outra Antiguidade, uma outra civilização, que temos de reconhecer na sua originalidade e julgar por si própria e não através de cânones de épocas anteriores”. Podemos assim pensar em acontecimentos singulares que a distinguem bastante dos séculos anteriores ou posteriores, diferentemente da visão de decadência que ainda vigora nos manuais escolares. Na verdade, se nos prendermos a reflexões que envolvam o conceito de "decadência do Império Romano”, compreender as transformações, as condições sociais, políticas e culturais dessa época se tornará um processo complicado ou até mesmo impraticável, pois, inconscientemente, nosso olhar será condicionado pela ideia de um Império em ruínas, o que é um equívoco. Todavia, se analisarmos a fase final do Império livre dessas premissas, refletindo sobre, por exemplo, a cultura, a sociedade e a religiosidade que se esboçam de maneira original nesse período, será possível encontrarmos, na Antiguidade Tardia, notáveis realizações que marcaram tanto o Ocidente quanto o Oriente.

Como exemplo da originalidade da Antiguidade Tardia, podemos citar os argumentos de Marrou (1979), ao analisar a diferença entre os primeiros séculos do Império e os séculos IV e V. O autor evoca, entre os quatro séculos e meio que os separam, dois homens bem representativos do seu tempo, Cícero e Agostinho. No plano da cultura, recorda que as obras de Cícero eram transcritas, coluna a coluna, em longos retângulos de papiro ou de pergaminho, enrolados em cilindro, que se iam desenrolando à medida da necessidade da leitura, para em seguida os enrolar de 
novo. ${ }^{2}$ Já na Antiguidade Tardia, o volumen cedeu lugar ao codex, isto é, ao livro que ainda hoje utilizamos, formado de cadernos cosidos, e que permite edições de tamanhos consideráveis, como a Cidade de Deus, de Agostinho, em um tempo no qual cada vez mais se difundia a leitura em silêncio, o que contribuiu para a suplantação do primado, por tanto tempo incontestado, da oratória.

De acordo com Marrou (1979: 17-23), houve também uma “revolução do vestuário” durante a Antiguidade Tardia. A veste principal por dentro da toga, a túnica, passou a ter costuras continuadas e ser solidamente fixada ao corpo, sendo assim muito menos ampla que a antiga roupa. Em contrapartida, no período clássico, utilizava-se uma grande peça de tecido flexível, presa por um colchete ou fíbula e sem mangas. Bustamante (2007: 5) declara que tais mudanças não se limitaram à ordem plástica, mas ecoaram profundamente na atitude psicológica e até moral. Impôs-se então uma diferente definição do pudor, acompanhada de uma sublimação do erotismo.

É com base em elementos como esses que pouco a pouco percebemos a originalidade e riqueza do mundo tardo-antigo. Contudo, não podemos deixar de caracterizar esse período em suas variadas facetas.

De forma concisa, aceitando-se que as elites romanas dos séculos III a V não viveram aterradas ante uma perspectiva de calamidade, podemos reconhecer sua prosperidade e a confiança que tinham em si mesmas, pois acreditavam na eternidade do Império, mesmo ante a ameaça dos povos vizinhos. Do mesmo modo, como afirma Peter Brown (1972), no

\footnotetext{
${ }^{2}$ A este modo rolo de papiro se dava o nome de volumem.
} 
Império do Ocidente a sociedade e a cultura eram dominadas por uma aristocracia senatorial cinco vezes mais rica, em média, do que os senadores do século I. As cidades do Império conheceram, na Antiguidade Tardia, uma fase de grande desenvolvimento, como vemos no caso de Antioquia e Constantinopla. ${ }^{3}$

A aristocracia da fase final do Império, contudo, já não era constituída de modo idêntico à dos séculos anteriores. Seus integrantes eram bem distintos dos antigos senadores da época do Principado. Dela participavam provinciais e membros provenientes das forças armadas. Dessa forma, uma das principais conquistas do século III manteve-se no século IV, isto é, a atribuição dos postos e a promoção baseadas apenas no mérito.

As alterações na estrutura social verificadas na Antiguidade Tardia também afetaram a religião oficial e as sensibilidades espirituais da sociedade romana, acontecimento tido como uma das principais transformações do período.

Entramos aqui num terreno que já tinha seus precedentes: a relação entre o paganismo e o cristianismo. Sabemos que já nos três primeiros séculos da Era Cristã, o paganismo vinha sofrendo modificações em seus rituais, mas é no IV século que a situação se agrava para os pagãos devido aos confiscos, interdições de sacrifícios, proibição de consulta a oráculos e visitação a templos, ao lado da promulgação de leis restritivas aos seus cultos, como a de 356, na qual era proibido, sob pena de morte, celebrar

\footnotetext{
${ }^{3}$ Sobre a cidade de Constantinopla, seu contexto, bem como a sua reforma e a da Igreja, mediante as críticas de João Crisóstomo, consultar os trabalhos de Gilvan Ventura da Silva: Um bispo para além da crise: João Crisóstomo e a reforma da Igreja de Constantinopla (2010) e O sentido político da prédica cristão no Império Romano: João Crisóstomo e a reforma da Cidade Antiga (2010a).
} 
sacrifícios, adorar os ídolos ou mesmo entrar em seus templos. No entanto, é em 392, pelas mãos de Teodósio, responsável por promulgar uma lei que, aplicada com rigor, proibia qualquer ato do culto pagão, mesmo o executado no interior das residências, que o paganismo sofrerá um duro golpe. No entanto, devemos estar atentos para não acreditar acriticamente na eficácia da legislação, pois possuímos séculos de experiência de não cumprimento das leis imperiais, o que não significa que a legislação imperial fosse de todo inócua, mas sim que as crenças e práticas religiosas não se transformaram subitamente.

\section{As mulheres romanas e suas "conquistas"}

Como mencionamos em nossa breve descrição acerca da Antiguidade Tardia, as mudanças de cunho político, religioso, econômico e sociocultural ocorridas a partir do século III alteraram bastante o modo de vida da sociedade romana, incluindo o papel das mulheres.

Durante o período republicano, e mesmo posteriormente, Roma se caracterizava por seu sistema patriarcal, no qual os homens concentravam o poder, a propriedade, as decisões políticas e econômicas, escreviam as leis, ditavam normas e pregavam a moral. A mulher, por sua vez, era submetida a tais ordenações, movimentando-se dentro de casa, onde educava a prole e servia como agente de reprodução (Ciribelli, 2002: 263). Em função de tal caracterização, é comum pesquisadores generalizarem a condição social da mulher, atribuindo a elas um papel subalterno. No entanto, acreditamos que generalizar o status feminino na Antiguidade não é a forma mais correta de o estudarmos, pois assim estaríamos negligenciando fatos históricos, muitas vezes em prol de uma simplificação que 
facilitaria resultados em uma dada pesquisa ou que reforçaria discursos absolutos de dominação masculina.

Mesmo na fase final da República, essa passividade atribuída às mulheres não ocorria em todos os casos. Alguns autores ressaltam que as mulheres se opuseram de variadas formas à opressão e ao poder masculino mesmo, na maior parte do tempo, estando confinadas ao espaço doméstico (Ciribelli, 2002: 263-264). Em determinado momento, Catão (Tito Lívio, História Romana. v. I.), acerca das atitudes das mulheres, alerta os políticos romanos: "Se elas tornarem-se iguais a vocês, elas o dominarão”. Achard (1995: 58) ressalta que “apesar de não gozarem de direitos políticos, as romanas chegaram a conseguir a supressão de leis que as prejudicavam, como a Lei Ópia, ${ }^{4}$ a Lei Vocônia, ${ }^{5}$ entre outras”.

A supressão da Lei Ópia, que proibia o luxo nas vestimentas utilizadas pelas mulheres, foi justificada por meio da tradicional divisão entre os gêneros, que consistia em relacionar o homem à política e à guerra; e a mulher ao adorno e à beleza, sendo, portanto, habituais os enfeites utilizadas pelas mulheres. Já a posição contrária defendia que as mulheres deviam se submeter aos seus maridos, não se manifestar, se restringir ao ambiente doméstico, manter o decoro, a discrição e a simplicidade (Bustamante, 2007: 3). Todavia, mediante a posição contrária de alguns homens,

${ }^{4}$ A Lei Ópia, adotada durante a II Guerra Púnica (218 - 201 a.C.), impunha uma série de restrições às mulheres romanas, dentre as quais se encontram: o limite à posse de quantidade de ouro pela e a proibição do luxo no vestir (Bustamante, 2007: 3).

${ }^{5}$ A Lei Vocônia proibia a instituição de uma mulher como herdeira, embora fosse filha única, casada ou não. Proibia também legar as mulheres mais da metade do patrimônio. 
bem como as manifestações públicas das aristocratas, ao final a lei Ópia foi revogada.

Não somente a supressão de leis contribuiu para as alterações na condição social das mulheres romanas, mas também mudanças no que concerne ao matrimônio. O casamento, ao longo da Roma Antiga, foi adquirindo novas concepções e modelos. Evocamos, como exemplo, o surgimento de uma nova modalidade de casamento jurídico, o sine manus, já que o cum manus caiu em desuso no final da República, como ressalta Gaio (I. 111). Esta modalidade era baseada na ideia de que a mulher, mesmo casando-se, permanecia sob a tutela de seu pai ou tutor. Diferentemente do cum manus, ela poderia dispor dos seus bens e até receber herança. Dessa forma, em caso de divórcio, a esposa receberia parte do dote, que antes era retido integralmente pelo marido, sendo também capaz de tomar decisões que antes não lhes eram permitidas devido à sua condição de dependência.

Como válvula de escape diante do poder masculino, muitas mulheres romanas não se dedicavam ao lar, fugiam ao dever da maternidade, opinavam em questões políticas e literárias, rompiam laços com seus familiares, tornavam-se prostitutas e apreciavam cultos estrangeiros, como o de Dionísios, Cibele, Ísis e Sérapis. Sua preferência por estes últimos deviam-se à acolhida e à iniciação que lhes eram oferecidas (Ciribelli, 2002: 265-269). ${ }^{6}$

${ }^{6} \mathrm{O}$ culto de Ísis pregava a igualdade dos sexos e a liberação para o amor. O que justifica as relações amorosas entre mulheres e poetas, como Cíntia e Propercio e Délia e Tibullo, que tinham se tornado adeptas ao culto (Achard, 1995: 62). 
Cadernos de Clio, Curitiba, n. ${ }^{\circ}$ 4, 2013

\section{A condição social das devotas cristãs na Antiguidade Tardia}

Como observamos acima, na fase final da República, as mulheres romanas obtiveram mudanças em sua condição social, por meio de concessões legais, por enfrentarem a situação que lhes era imposta e por alterações nas tradições. Ao chegarmos na Antiguidade Tardia, verificamos diversas outras transformações.

As mulheres tardo-antigas não podiam, como de costume, exercer participação na vida política, a menos que fossem membros da casa imperial. Tradicionalmente, se esperava das mulheres romanas que cultuassem as virtudes tradicionais da modéstia, castidade e devoção aos deuses e à família, devendo ser protegidas da exploração de sua fraqueza por tutores indignos (Siqueira, 2001: 4). Entretanto, elas não viviam isoladas em suas residências, estavam sempre fisicamente presentes, tanto na vida doméstica, como na vida pública.

As mulheres romanas, mesmo em finais da República, participavam de banquetes e reuniões sociais importantes. De modo diverso das gregas, tinham o direito de propriedade e podiam até mesmo fundar negócios e, futuramente mosteiros. Embora, como dito anteriormente, não pudessem votar ou ser eleitas, algumas inscrições encontradas na cidade de Pompeia mostram que as mulheres não se continham em apoiar seus candidatos aos cargos públicos, o que demonstra, em algum grau, sua notabilidade e influência social. Segundo Funari (2001: 104-107) “há mesmo indícios de que havia mulheres de posses que pagavam pelos serviços de prostíbulos”. Tais reflexões, consequentemente, nos levam a ponderar sobre a visão tradicional e estereotipada da figura feminina presa ao lar em Roma. 
Apesar do esforço em constituir temas referentes às mulheres na Antiguidade Tardia, ainda sofremos com a limitação da documentação, já que poucas são as fontes escritas por mulheres às quais temos acesso. Por outro lado, existe uma abundância de fontes documentais que trazem um olhar dos homens sobre elas. E é com base nesse olhar masculino sobre as mulheres que podemos ter ideia também de seus defeitos, ou ao menos ponderar sobre o que os romanos consideravam como defeitos.

Muitos são os depoimentos que qualificam as mulheres como seres que falam muito e se preocupam demasiadamente com sua aparência, necessitando de auxílio para conter seus impulsos. Por outro lado, quando são cabíveis elogios a elas, mencionam que há mulheres boas, que são fiéis, modestas e competentes em sua vida doméstica e conseguem agir conforme os princípios morais (Siqueira, 2001: 4). Talvez, devido a esses “elogios” é que se costuma apontar um papel genérico para as mulheres romanas.

Siqueira (2001: 5) ressalta que algumas dessas questões foram confrontadas pelos cristãos. No entanto:

[...] o cristianismo, assim como outras religiões da mentalidade predominante, mantêm a mesma postura com relação à mulher. A reivindicação Cristã que os homens e mulheres são espiritualmente iguais não teve nenhuma conseqüência mais prática, assim como a reivindicação filosófica que as mulheres podem manifestar as mesmas virtudes como os homens.

Concordando com o trecho acima e numa tentativa de explicar os motivos para a permanência da postura masculina frente às mulheres, mesmo com o advento do cristianismo, Silva (2006: 306-307) declara que 
há uma distinção entre o plano místico e o plano terreno. Portanto, "se no plano místico se pode pretender uma igualdade entre todos os homens, no plano terreno, hodierno, as mulheres, como herdeiras de Eva que são, devem se conformar com a sua posição secundária diante do homem”. Tal hipótese explica, em grande parte, a rígida atuação eclesiástica cristã, que dificultava a concessão de maior participação e visibilidade das mulheres nas cerimônias litúrgicas. No entanto, é a partir desse momento de redefinição do lugar ocupado pelas mulheres no âmbito eclesiástico que ocorre a ascensão das viúvas, virgens e diaconisas, dentro da ekklesia.

Nesse sentido, podemos dizer que, se o cristianismo não propôs, em absoluto, a igualdade entre os gêneros, ele porém abriu as portas para novas atividades, ou simplesmente modificou e utilizou as existentes, possibilitando às mulheres diferentes formas de prestar devoção à suas crenças, como, por exemplo, o movimento monástico.

Silva (2007: 63-64) ressalta que o monacato, que começou a se esboçar por volta de 270, porém expandindo-se mais fortemente nos séculos IV e $\mathrm{V}$, concedeu mais oportunidades para certas mulheres exercerem a sua devoção fora do âmbito familiar, tendo como ponto de convergência os mosteiros, onde se encontravam virgens, devotas, viúvas e diaconisas, que deixavam seus lares a fim de viver reclusas. Essas mulheres tinham maior oportunidade de se diferenciar das tradicionais matronas romanas, pois se libertariam, parcialmente, do jugo masculino.

Siqueira (2001: 5), da mesma forma, declara que o cristianismo introduziu uma prática que, ao unir homem e mulher em um compromisso com Deus, podia suscitar o abandono dos deveres com a família e o Estado: 
Pela primeira vez, algumas mulheres podiam rejeitar o casamento e a gravidez, e viver em casa com suas mães, ou em solidão, ou em uma comunidade de mulheres. A oração e estudo de Bíblia podiam deslocar os afazeres da vida doméstica, as mulheres sempre puderam participar em cultos religiosos e fazer oferecimentos aos deuses, podiam alcançar fama duradoura dedicando à Igreja e ao serviço de Deus.

Podemos dizer então que, por meio do cristianismo, algumas mulheres passaram de uma situação opaca para uma de emergente visibilidade, na qual o reconhecimento não era adquirido somente por seguir as virtudes propostas para uma vida doméstica, mas também por sua devoção ao culto cristão e por práticas do asceticismo. Essas mulheres, reconhecidas pela sua atuação em prol do cristianismo, também foram mencionadas nas fontes gregas e latinas, constantemente elogiadas por darem comida e vestirem os pobres, os salvarem da morte e nutrir profunda admiração por importantes figuras, como os bispos e os ascetas.

Em meio ao cenário de cristãs devotas e piedosas inseriam-se as viúvas. Consideradas modelos de devoção, formavam uma associação em suas comunidades, geralmente reunidas sob o comando de uma delas. Existiam ainda as virgens, que ocupavam um lugar privilegiado na ekklesia, pois apareciam após o clero, os monges e as crianças durante as procissões. Assim como as viúvas, as virgens não constituíam uma ordem, já que não ofereciam oblação e nem serviços litúrgicos (Berardino, 2002).

Além das viúvas e virgens, existiam, no Oriente, mulheres que eram ordenadas diaconisas. Em suma, eram elas responsáveis pelo apoio às catecúmenas e às novas cristãs, bem como pelos serviços litúrgicos. Além disso, podiam ser mensageiras; deviam estar presentes quando uma mulher vinha procurar um diácono ou o bispo; deveriam acolher mulheres 
nas assembleias; prestar ajuda aos pobres e necessitados e zelar, assim como os diáconos, pela boa ordem nas reuniões. Contudo, a ação das diaconisas era limitada, pois não poderiam realizar as tarefas confiadas aos presbíteros e aos diáconos, consideradas de maior importância. Elas apenas assistiam os presbíteros na administração do batismo, por uma questão comportamental e de decência.

\section{As aristocratas cristãs e sua influência social}

Assim como descrito por Silva (2007: 86), em sua análise da História Lausíaca, Paládio menciona um conjunto de mulheres que, fazendo parte da elite, se notabilizaram pela admirável devoção à causa cristã. Um caso bem conhecido é o de Melânia, a Jovem, que, dentre suas ações caritativas, teria distribuído no Egito, em Antioquia e na Palestina grande quantidade de moedas de ouro. Teria ainda vendido suas posses na Espanha, Aquitânia, Tarragona e Gália, retendo apenas aquelas da Sicília, Campânia e África, cujos rendimentos reservou à manutenção dos conventos. Além disso, providenciou também a libertação de oito mil escravos.

Outro caso notável é o de Olímpia. Pertencente a uma família aristocrática de Constantinopla recém-enobrecida, filha de Seleuco, um comites, e supostamente descendente de Ablábio, ela é um excelente exemplo de mulheres que, na Antiguidade Tardia, obtiveram uma posição de destaque. Olímpia, órfã desde a infância, recebeu uma educação cristã, sob a supervisão da irmã do bispo Anfilóquio, Teodósia, integrante de um grupo de mulheres cristãs piedosas. Olímpia tornou-se viúva prematuramente, o que favoreceu sua adesão ao ascetismo cristão. Ela também foi benfeitora 
do bispo Nectário, que a ordenou diaconisa da igreja de Constantinopla, como também partidária de João Crisóstomo, de quem foi amiga intíma.

Olímpia, em sua condição de patrocinadora de obras de caridade, teria doado à igreja dez mil quilos de ouro, vinte mil de prata, e todos os seus bens imóveis situados nas províncias da Trácia, Galácia, Capadócia Prima e Bitínia, mais as casas pertencentes a ela na Capital, e uma situada perto da catedral, chamada de “a casa de Olímpia”, juntamente com a casa da tribuna, com banheiros, e todos os edifícios perto dele, um moinho e uma casa localizada próximo aos banhos públicos de Constantinopla, além de outra, que era chamada de a "casa de Evandro", assim como também todas as suas propriedades suburbanas (Vita Olympiadis).

Os casos de Melânia e Olímpia, evidentemente não são os únicos. Como ressalta Silva (2007: 86):

Paula, responsável pelo funcionamento de um mosteiro com 50 virgens na Palestina; Asela, uma virgem reconhecida como patrona de conventos e Melânia, a Antiga, fundadora de um mosteiro para mulheres em Jerusalém, cumprem, do mesmo modo, o papel de patronas veneráveis da Igreja.

Tais mulheres, frequentemente, estavam associadas a círculos aristocráticos do Império Romano, na condição de esposas, filhas ou viúvas de destacados membros da elite. Venéria, por exemplo, era esposa do comites Valovico. Melânia, a Antiga, era filha do ex-cônsul Marcelino, enquanto Olímpia é filha do ex-comites Seleuco. Na qualidade de detentoras de vastos patrimônios, elas se tornaram célebres por consumir toda a sua riqueza na conservação de igrejas, mosteiros e hospedarias e na assis- 
tência prestada a monges, enfermos, prisioneiros, a bispos e nas celebrações do culto cristão (Silva, 2007: 86).

\section{Considerações finais}

Nossa tentativa, no momento, foi a de visualizar as mulheres romanas como sujeito social, bem como sua atuação com percursos próprios, agindo ou reagindo conforme os fatos históricos vão se construindo. No entanto, como ressaltamos, a despeito das inúmeras pesquisas, dissertações e teses, ainda sofremos com a escassez de fontes que nos dêem acesso ao pensamento das mulheres e não ao pensamento dos homens sobre elas. Sabemos da dificuldade em tratar de temas referentes ao feminino na Antiguidade. Muitas lacunas ainda necessitam ser preenchidas, pois é mediante discursos masculinos que o feminino é constantemente representado: nos mitos, na poesia, na história, nos romances, nos tratados médicos e filosóficos, na legislação, na iconografia, entre outros suportes (Siqueira, 2001: 2). Nessa imensidão documental destacam-se as imagens. Contudo elas não nos proporcionam uma visão direta das mulheres, mas sim a representação masculina sobre elas (Duby; Perrot, 1990: 8).

Desse modo, muitos historiadores, como Siqueira (2001: 2-3) e Funari (1995: 179-200) declaram que, para a construção de uma História das Mulheres na Antiguidade, é fundamental uma análise holística, interdisciplinar, que abarque os estudos sobre Literatura, Língua, Antropologia, Arqueologia, História da Arte, entre outras especialidades.

Analisando a relação das mulheres e a expansão do cristianismo, percebemos que o Império Romano passou por graduais transformações, incluindo as de caráter religioso. Nesse contexto, muitos romanos, busca- 
ram consolo em suas crenças místicas. No entanto, a religião oficial já não lhes propiciava mais a paz de espírito que costumava oferecer, o que levou a um crescimento no número de adeptos de outras crenças, como o cristianismo (Funari, 2001: 131). Além das camadas inferiorizadas, o culto cristão começou a angariar adeptos também entre membros da aristocracia romana, a começar pelas mulheres da elite, marginalizadas nas religiões tradicionais, mas encontrando espaço na nova religião, marcando, então, um processo de assimilação entre o cristianismo e as mulheres.

Acreditamos que as mudanças sociais que ocorriam na vida das mulheres romanas é algo a se ponderar, pois é natural que, com o passar de séculos, o contato com novos povos e culturas, assimilações e tensões produziram alterações nos papéis sociais e na representação da figura feminina. Mesmo com a difusão do cristianismo, de modo geral, as mulheres permaneceram em caráter secundário dentro da Igreja. Entretanto, o cristianismo contribuiu para a redefinição do lugar feminino nas comunidades cristãs e no Império Romano. Como mencionamos, colocando-se a serviço da Igreja, as mulheres tinham a chance de abnegar o casamento e assim escapar do papel tradicional de mãe e de esposa; poderiam viver reclusas em mosteiros, praticar cultos e dedicar-se ao ascetismo, como diaconisas, virgens, viúva, monjas ou devotas, o que lhes permitiria certo reconhecimento.

Por fim, a representação e o papel feminino na Antiguidade Tardia são variáveis, pois se transformam dependendo das condições sociais em que os analisamos. Das escravas que cuidavam e amamentavam os recémnascidos às matronas que desempenhavam seus papéis domésticos e cumpriam com as virtudes que se esperavam delas; das mulheres entregues à 
prostituição às ascetas, todas essas mulheres tinham funções diferentes dentro da sociedade, e eram tratadas e vistas de acordo tais funções. Seus papéis e condições sociais poderiam diferenciar-se, porém, havia algo em comum entre elas: todas contribuíram, ao seu modo, para dinâmica da sociedade romana.

\section{Referências}

\section{Documentação primária impressa}

ANONIMOUS. Life of Olympias. In: CLARK, E. A. (Ed.). Jerome, Chrysostom, and friends: essays and translations. Lewiston: Edwin Mellen Press, 1979.

GAIO. Commentarius Primus. In: F. KNIEP (Ed.). Gai institutionum commentarius primus, Jena, 1911.

TITO LÍVIO. História Romana. v. I. São Paulo: Paumape, 1989.

\section{Obras de apoio}

ACHARD, G. La femme a Rome. Paris: PUF, 1995.

ALEXANDRE, Monique. Do anúncio do Reino à Igreja: papéis, ministérios, poderes femininos. In: DUBY, Georges; PERROT, Michelle (Orgs.). História das mulheres no Ocidente: a Antiguidade. Porto: Afrontamento, 1993. v.1, p. 511-548.

BERARDINO, A. Dicionário patrístico e de antiguidades cristãs. Petrópolis: Vozes, 2002.

BROWN, P. O Fim do Mundo Clássico: de Marco Aurélio a Maomé. Lisboa: Verbo, 1972.

BUSTAMANTE, R. M. da C.. Toalete feminina na Antigüidade Tardia: entre imagem e escritos. VII Seminário Internacional Fazendo Gênero, Florianópolis: Mulheres, 2006. v.1, p. 1-8. 
CAIXETA, J.; BARBATO, S.. Identidade feminina: um conceito complexo. Paideia, Ribeirão Preto, vol. 14, n 28, 2004.

CIRIBELLI, M. C.. Emancipação e liberação sexual das mulheres na República Romana (II e I séculos a.C.). Phoînix, Rio de Janeiro, ano 8, vol. 8, p. 259-278, 2002.

CONDILO, C. S. A identidade feminina na historiografia sobre as mulheres da Grécia Antiga. Alétheia, Porto Alegre, vol. 1, 2009.

DUBY, Georges; PERROT, Michelle (Orgs.). História das Mulheres no Ocidente: a Antiguidade. Porto: Afrontamento, 1993. v.1.

FUNARI, P. P. A. Romanas por elas mesmas. Cadernos Pagu, 5, Campinas: IFCH/UNICAMP, p. 179-200, 1995.

Grécia e Roma. São Paulo: Contexto, 2001.

MARROU, H. I. Decadência romana ou Antiguidade Tardia? Lisboa: Aster, 1979.

SILVA, Gilvan Ventura da. A redefinição do papel feminino na Igreja Primitiva: virgens, viúvas, diaconisas e monjas. In: SILVA, G. V. da; NADER, M. B.; FRANCO, S. P. (Orgs.) As identidades no tempo: ensaios de gênero, etnia e religião. Vitória: Edufes, 2006.

. Ascetismo, Gênero e Poder no Baixo Império Romano: Paládio de Helenópolis e o status das Devotas Cristãs. História, São Paulo, v. 26, n.1, p. 63-78, 2007.

O sentido político da prédica cristã no Império Romano: João Crisóstomo e a reforma da cidade antiga. In: ARAÚJO, S. R. de.; ROSA, C, B. da; JOLY, Fábio D (Orgs.). Intelectuais, poder e política na Roma Antiga. Rio de Janeiro: NAU: FAPERJ, 2010a, p. 235-272.

. Um bispo para além da crise: João Crisóstomo e a reforma da Igreja de Constantinopla. Phoînix, Rio de Janeiro, ano 16, vol. 16, nº 1, p. 109-127, 2010.

SIQUEIRA, Silvia M. A.. Considerações sobre o tema mulher na Antigüidade. Anais do IV Congresso Nacional de estudos Clássicos/XII Reunião da SBEC, Ouro Preto, 2001.

. Reflexões sobre política e igreja no século IV: um olhar para as mulheres cristãs. Dimensões, Vitória, vol. 25, p. 148-163, 2010. 